\title{
RECRYSTALLIZATION TEXTURE OF PLANE STRAIN COMPRESSED ALUMINUM SINGLE CRYSTAL
}

\author{
DONG NYUNG LEE \\ Division of Materials Science and Engineering, and Center for Advanced \\ Materials Research, Seoul National University, Seoul 151-742, Korea
}

(Received 10 January 1996)

\begin{abstract}
Butler, Blicharski and Hu found a rotated cube recrystallization texture after annealing an aluminum crystal with the (112)[11ī] and (112)[111] deformation texture, which was obtained by plane strain compressing the aluminum single crystal with an initial orientation of (001)[110]. The unexplained formation of the rotated recrystallization has been discussed based on a recrystallization model recently suggested by the present author.
\end{abstract}

KEY WORDS: Aluminum, single crystal, plastic deformation, recrystallization, rotated cube texture, theoretical model.

\section{INTRODUCTION}

Heavily cold rolled aluminum polycrystals are known to develop the cube texture upon recrystallization. Butler, Jr., Blicharski and $\mathrm{Hu}$ (1991) undertook investigation to understand the origin of the cube texture in fcc metals. An aluminum single crystal with an initial orientation of (001)[110], which is known to be unstable, was deformed using a channel - die device to impart homogeneous plane strain compression. A reduction of $70 \%$ made the crystal rotate about its [110] axis in the

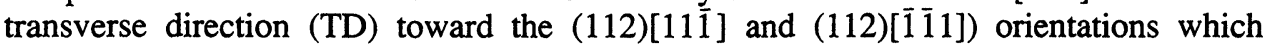
are characteristic of the copper type rolling textures, as shown in Figure 1. The orientations remained stable at least to $90 \%$ reduction. The recrystallization texture produced after annealing for five minutes at $200^{\circ} \mathrm{C}$ was a rotated cube texture away from the ideal cube texture, (001)[100], as shown in Figure 2. They could not explain the formation of the rotated cube texture.

Two principal theories exist (see Doherty et al., 1988) for the interpretation of recrystallization textures (RT). They are the theory of oriented nucleation, in which the preferred activation of some special nuclei determines the final recrystallization texture; and the theory of oriented growth, in which only grains having the best orientation relationship to the deformed matrix can grow and form the recrystallization texture.

Recently the present author (Lee, 1995) proposed a model for the recrystallization texture. The recrystallization process basically occurs to reduce the energy stored during deformation. The stored energy may include energies due to vacancies, 

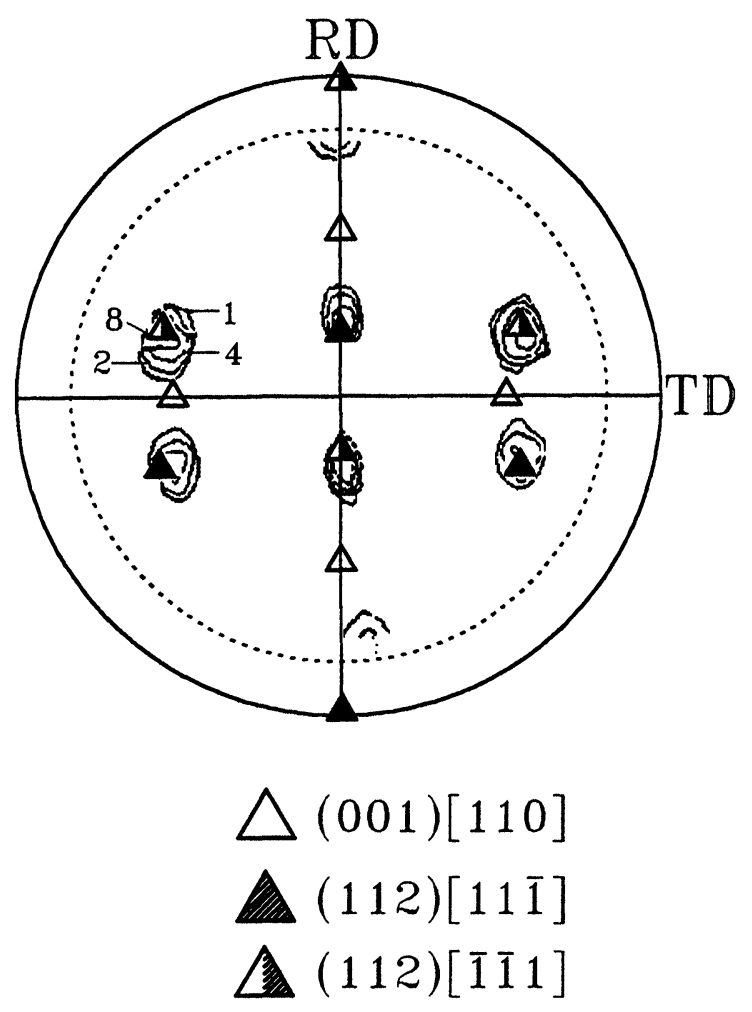

Figure 1 (111) pole figure of an aluminum single crystal with initial orientation (001)[110] after $70 \%$ reduction by channel - die compression (Butler, Blicharski and $\mathrm{Hu}, 1991$ ).

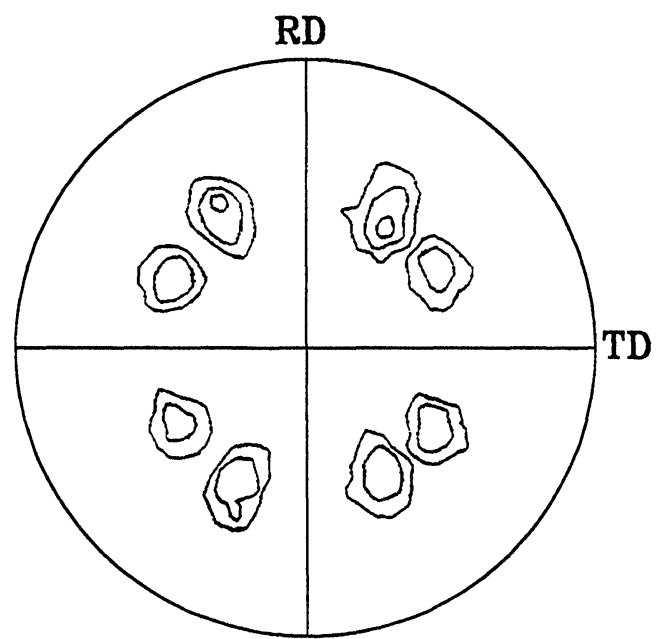

Figure 2 (111) pole figure of fully recrystallized single crystal (001)[110] after 90\% reduction by channel - die compression and subsequent annealing at $200^{\circ} \mathrm{C}$ for five minutes (Butler, Blicharski and $\mathrm{Hu}, 1991)$. 
dislocations, grain boundaries, surface energies, etc. The energy is not directional, but the texture is directional. Understanding the sources of the directionality of the recrystallization texture may be a solution of the recrystallization texture. An effect of anisotropy of free surface energy due to differences in lattice surface energies can be neglected except in the case of the grain size being much larger than the specimen thickness in vacuum or an inert atmosphere. Differences in the mobility of grain boundaries must be an important factor to consider in the texture change during grain growth. Vacancies do not seem to have an important effect on the recrystallization texture due to their relatively isotropic characteristics. Therefore the most important driving force for recrystallization must be the stored energy due to dislocations. No matter how high the energy may be, dislocations cannot directly be related to the recrystallization texture, unless they give rise to some anisotropic characteristics. The deformation mode can determine alignment of dislocations. The dislocation alignment is very complicated. However, if we approximate the alignment by a simple arrangement of edge dislocations, then we can obtain the absolute maximum stress direction. The absolute maximum stress direction becomes the direction of the minimum elastic modulus of recrystallized grains, whereby the strain energy of the related constant volume system can be minimized.

This concept could explain many well known recrystallization textures of fcc and bcc metals (Lee, 1995), the formation of recrystallization textures from different rolling textures of an interstitial free steels (Park et al.), and the development of recrystallization textures from the shear textures of aluminum (Choi et al.) and copper (Hong et al.) sheets.

The objective of this paper is to discuss the unexplained rotated cube recrystallization texture in Figure 2.

\section{DISCUSSION}

In order to obtain the absolute maximum principal stress direction, we have to know operating slip systems. The operating slip systems can be obtained using the well-known full constraint Taylor-Bishop-Hill theory. For the aluminum single crystal with an initial orientation of (001)[110] which is plane strain compressed with its $[\overline{1} 10]$ axis in the transverse direction, the active slip systems are (111)[10 $\overline{1}],(111)[01 \overline{1}],(\overline{1} \overline{1} 1)[0 \overline{1} \overline{1}]$ and $(\overline{1} \overline{1} 1)[\overline{1} 0 \overline{1}]$. They are shown in Figure $3 a$. The (001)[110] orientation is known to be unstable upon plane strain compression and to rotate about its $[\overline{1} 10]$ axis in the transverse direction toward the (112)[11 $\overline{1}]$ and $(112)[\overline{1} \overline{1}]$ orientations, which are shown in Figure $3 b$. For the (112)[11i]

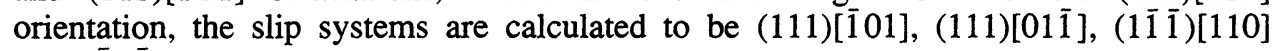
and $(\overline{1} 1 \overline{1})[110]$, which are drawn in Figure $3 b$.

Variations of shear strains on slip systems of $(111)[10 \overline{1}],(111)[01 \overline{1}],(\overline{1} \overline{1} 1)[0 \overline{1} \overline{1}]$, $(\overline{1} \overline{1})[\overline{1} 0 \overline{1}],(1 \overline{1} \overline{1})[110]$ and $(\overline{1} 1 \overline{1})[110]$ with rotation angle about $[\overline{1} 10]$ from the (001)[110] orientation to the (112)[11i] orientation have been calculated using the Taylor-Bishop-Hill theory. The calculated results are shown in Figure 4. The (111)[10ĩ] and (111)[01ī] slip systems remain to operate with their maximum shear strain at $10^{\circ}$ during the rotation. The slip systems of $(\overline{1} \overline{1} 1)[0 \overline{1} \overline{1}]$ and $(\overline{1} \overline{1} 1)[\overline{1} 0 \overline{1}]$ cease to act at $10^{\circ}$, while the $(1 \overline{1} \overline{1})[110]$ and $(\overline{1} 1 \overline{1})[110]$ slip systems start to be activated at $10^{\circ}$, reaching their maxima at the (112)[111] orientation. 


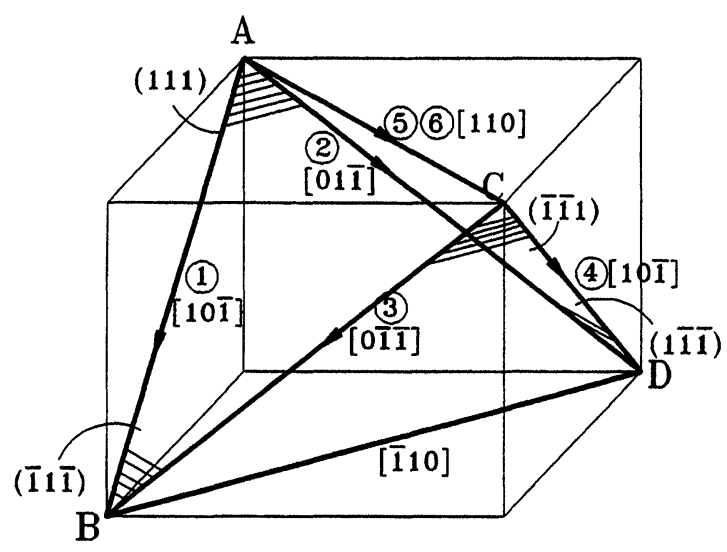

(a)

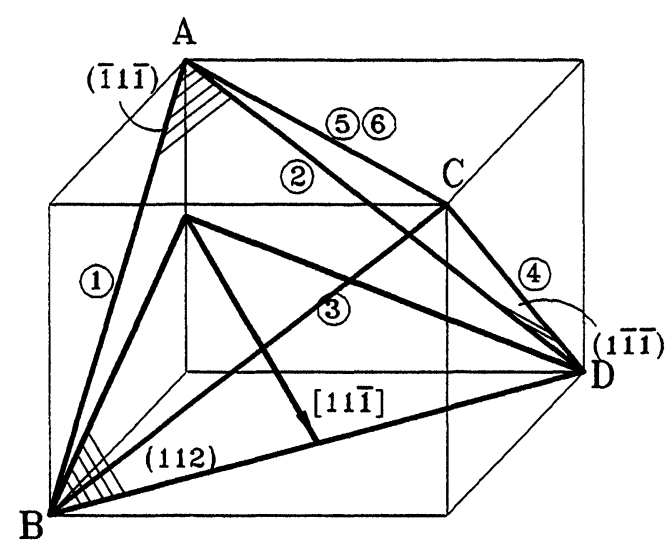

(b)

Figure 3 Active slip systems of aluminum single crystals with orientations of (a) (001)[110] and

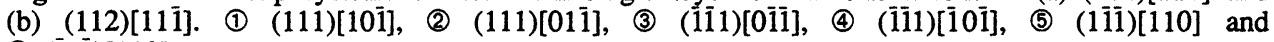
(6) (11i) $[110]$.

The contribution of the slip systems to the deformation can be approximated to be proportional to the area under the related shear strain - rotation angle curves, $\int \gamma_{\mathrm{i}} \mathrm{d} \theta$ with $\gamma_{\mathrm{i}}$ and $\theta$ being shear strain of the $\mathrm{i}$ slip system and rotation angle, respectively. The area ratio is calculated to be as follows:

$$
\int_{0}^{35} \gamma_{1} \mathrm{~d} \theta: \int_{0}^{10} \gamma_{3} \mathrm{~d} \theta: \int_{10}^{35} \gamma_{5} \mathrm{~d} \theta=30: 3: 20.6
$$

where 1,3 and 5 stand for the $(111)[10 \overline{1}]$ or $(111)[01 \overline{1}]$, the $(\overline{1} \overline{1} 1)[0 \overline{1} \overline{1}]$ or $(\overline{1} \overline{1})[\overline{1} 0 \overline{1}]$, and the $(1 \overline{1} \overline{1})[110]$ or $(\overline{1} 1 \overline{1})[110]$ slip system. All the slips may not occur on the related slip systems homogeneously in a large single crystal. Some regions of the crystal may be deformed by the (11)[10i ], ( $\overline{1} \overline{1} 1)[0 \overline{1} \overline{1}]$ and $(1 \overline{1} \overline{1})[110]$ 


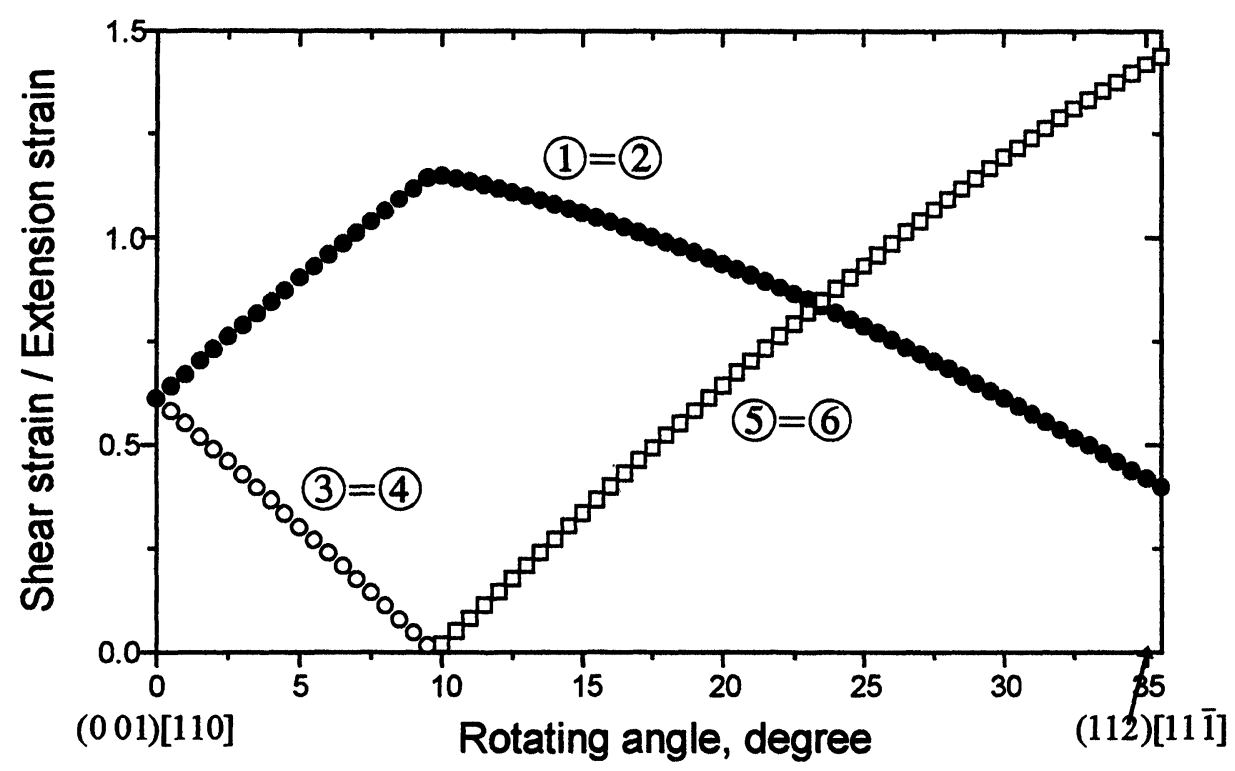

Figure 4 Shear strains on slip systems of (1) (111)[10i]], (2) (111)[01ī], (3) (īī1)[0īi ],

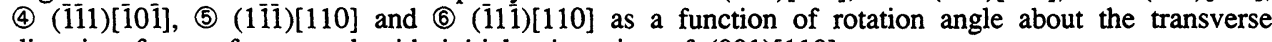
direction for an fcc crystal with initial orientation of (001)[110].

slip systems, while some other regions on the (111)[01 $\overline{1}],(\overline{1} \overline{1} 1)[\overline{1} 0 \overline{1}]$ and $(\overline{1} 1 \overline{1})[110]$ slip systems. The slip directions of the former three slip systems and of the latter three slip systems make one triangle each.

According to the Lee model [3], the absolute maximum stress direction is parallel to the slip direction for a single slip system being activated. When multiple slip systems are activated, the related slip directions are added to obtain the maximum absolute stress direction. Thus, for the contribution of the (111)[10i $],(\overline{1} \overline{1} 1)[0 \overline{1} \overline{1}]$ and

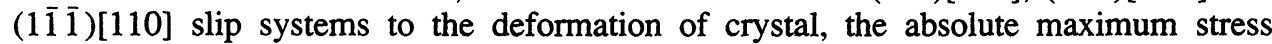

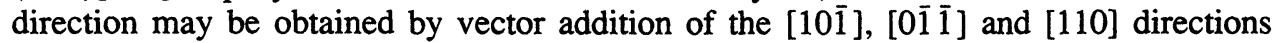
whose contributions are assumed to be proportional to the area ratio obtained earlier, that is, $30: 3: 20.6$. The vector addition is shown in Figure 5. It is found that the resultant direction pass through point $E$ which devides line $B C$ by a ratio of 1 to 2 . The Lee model suggests that direction $\mathrm{AE}$, the absolute maximum stress direction in the deformed state, is parallel to $\langle 100\rangle$ of recrystallized grains which are the minimum Young's modulus directions of aluminum.

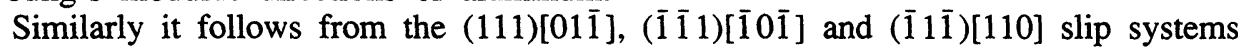
that another absolute maximum stress direction AF can be obtained, which are shown in Figure 6. Direction AF must be parallel to $<100\rangle$.

Therefore, plane AEF, which is parallel to the rolling plane (112), must be $\{100\}$ after recrystallization [let us designate (001)], and the rolling direction AG (originally [111] must be away from direction $\mathrm{AE}$ or $\mathrm{AF}$, which becomes one of $\langle 100\rangle$ after recrystallization, through $22^{\circ}$. The calculated recrystallization texture is plotted in (111) pole figure, along with measured data and indices Butler et al. obtained, in Figure 7. The calculated results are in good agreement with the measured data. 


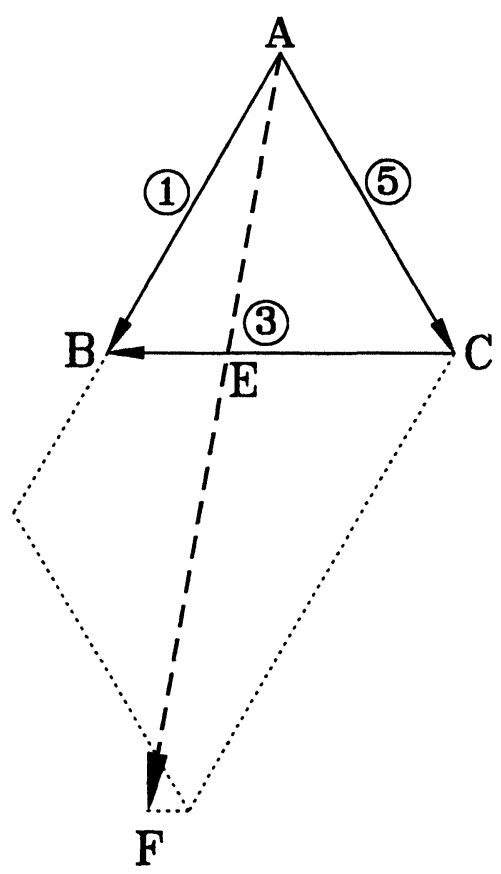

Figure 5 Vector addition of slip directions of (1) [10i]], (3) [0īi], (5) [110] assuming that their contribution ratio is $30: 3: 20.6$. Points $\mathrm{A}, \mathrm{B}$ and $\mathrm{C}$ are equivalent to $\mathrm{A}, \mathrm{B}$ and $\mathrm{C}$ in Figure 3 . $\overline{\mathrm{BE}}: \overline{\mathrm{EC}}=1: 2$.

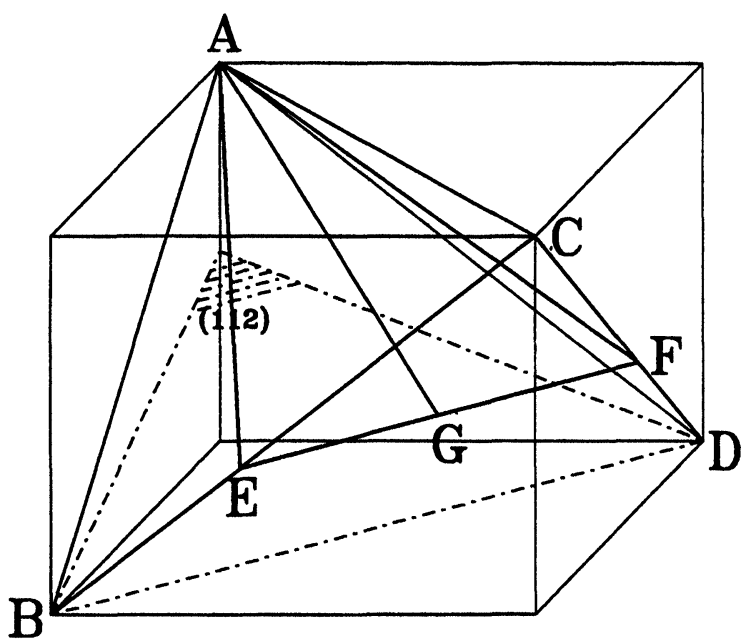

Figure 6 Various directions and planes with respect to the (112)[11i] orientation.

$\mathrm{BE}: \mathrm{EC}=!: 2$

FD : FC $=1: 2$

plane AEF // (112)

$\angle \mathrm{EAG}=\angle \mathrm{FAG}=22^{\circ}$ 


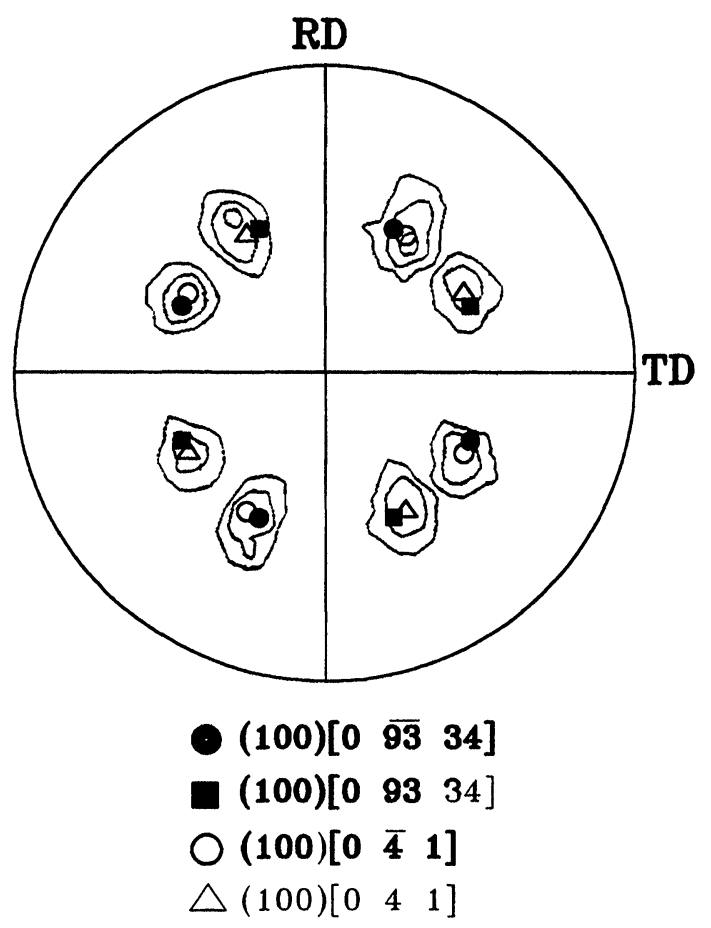

Figure 7 (111) pole figure showing measured (contours) and calculated $(\mathbf{0}, \mathbf{a}$ ) recrystallization textures. $(O, \triangle$ : indexed by Butler et al. (1991)).

\section{CONCLUSION}

The rotated cube recrystallization texture obtained from the plane strain compression of aluminum single crystal with an initial orientation of (001)[110] could be well explained by relative contributions of slip systems involved in the deformation.

\section{Acknowledgment}

This work has been supported by Korea Science and Engineering Foundation through RETCAM, Seoul National University. The author would like to appreciate valuable comments and discussions Dr. C.-H. Choi and Mr. S.-H. Hong at Seoul National University have made.

\section{References}

Butler, I. J. F. Jr., Blicharski, M. and Hu, H. (1991). Textures and Microstructures, 14-18, 611. Choi, C. H., Hong, S. H. and Lee, D. N. to be published.

Doherty, R. D., Gottstein, G., Hirsch, J., Hutchinson, W. B., Lücke, K., Nes, E. and Wilbrand, P. J. (1988). Proc. ICOTOM-8. Eds. J. S. Kallend and A. Gottstein. The Metallurgical Soc. Warrendale. p. 563.

Hong, S. H., Choi, C. H. and Lee, D. N. to be published.

Lee, D. N. (1995). Scripta. Met. 32, 1689.

Park, Y. B. Gottstein, G. and Lee, D. N. (1996). Mat. Sci. Eng. 